\title{
Development Perspectives of Power to Gas (P2G) in Spain
}

\author{
I. Saboya, L. Rouco and P. Linares \\ Universidad Pontificia Comillas \\ Alberto Aguilera, 23, 28015 Madrid, Spain \\ P. Cortés, F. Ferragut, M. P. Martínez, F. García and J. Chamberlain \\ Gas Natural Fenosa \\ Avenida de San Luis, 77, 2803 Madrid, Spain
}

\begin{abstract}
Wind generation curtailments can occur in power systems as wind penetration increases. An alternative to curtailments is Power to Gas (P2G). The fundamental idea of $\mathrm{P} 2 \mathrm{G}$ is to use the surplus energy, that cannot be incorporated to the power system, to produce hydrogen (H2) using an electrolysis process. The hydrogen is reacted with $\mathrm{CO} 2$ to produce methane $(\mathrm{CH} 4)$ that can be injected to the natural gas pipeline network. Hence, natural gas is used an energy store system. This paper presents the results of a study of the development perspectives of $\mathrm{P} 2 \mathrm{G}$ in Spain.
\end{abstract}

Keywords. Power to Gas, wind generation curtailments, internal rate of return.

\section{Introduction}

One of the pilars of the European strategy on reductions of $\mathrm{CO} 2$ emissions is the development of renewable energy sources. The distinct feature of some of renewable energy sources (wind, solar) is their intermittent and nondispatchable nature. Despite of the progress for the increase of penetration of renewable energy sources in power systems, some limitations still exist and Transmission System Operators impose limits to the penetration of renewable energy sources in some scenarios of the power system operation and in some areas of the system as well. It results in curtailments of wind generation.

An alternative to curtailments that it is being paid attention is called "Power to Gas (P2G)" [1]. The fundamental idea of $\mathrm{P} 2 \mathrm{G}$ is to use the surplus energy, that cannot be incorporated to the power system, to produce hydrogen (H2) using an electrolysis process. The hydrogen is reacted with $\mathrm{CO} 2$ to produce methane $(\mathrm{CH} 4)$ that can be injected to the natural gas pipeline network. Hence, natural gas is used an energy store system.

This paper presents the results of a study of the development perspectives of $\mathrm{P} 2 \mathrm{G}$ in Spain. The study has comprised: the estimation of wind generation curtailments in future scenarios of the Mainland Spain power system (2020 and 2030), the identification of the $\mathrm{CO} 2$ sources and the economic analysis of typical $\mathrm{P} 2 \mathrm{G}$ plants. The key part of the study is the estimation of wind generation curtailments in future scenarios of the Mainland Spain power system. The ROM model has been used for such purpose [2].

The paper is organized as follows: section 2 reviews past wind generation curtailments in the mainland Spanish power system; section 3 describes the ROM model and its validation by comparing actual and simulated operation of 2014 scenario of the Mainland Spain power system; section 4 estimates future wind generation curtailments in 2020 and 2030 scenarios of the Mainland Spain power system; section 5 contains results of the economic analysis of a $\mathrm{P} 2 \mathrm{G}$ plant; section 6 provides the conclusions of the paper.

\section{Review of past wind generation curtailments in the Mainland Spain power system}

This section reviews past wind generation curtailments in Mainland Spain power system. Wind generation curtailments in the Mainland Spain power system can occur in two different circumstances:

- In operation planning. In case of constraints imposed by the lack of grid capacity. Grid constraints are identified after the daily market clearing.

- In real time operation. In case of constraints due to by the system constraints (lack of upward and downward reserves). System constraints and identified in real time operation.

The Spanish Transmission System Operator (Red Eléctrica de España) provides through the information system of the system operator detailed information of the wind generation curtailments [3]. Figure 1 shows the variation of wind generation curtailments in due to grid constraint management after the daily market clearing from 2011 through 2014. Wind generation curtailments are around $20 \mathrm{GWh}$ per year. 


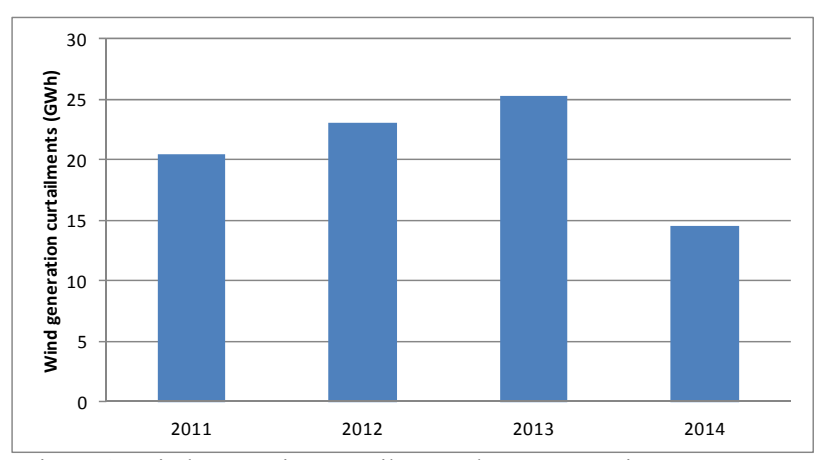

Figure 1: Wind generation curtailments due to constraint management after the daily market clearing.

Figure 2 depicts the variation of wind generation curtailments is due to system constraint management in real from 2011 through 2014. They depend very much on the year. Wind generation curtailments were more than $1000 \mathrm{GWh}$ in 2012 and about $500 \mathrm{GWh}$ in 2014. Hence, curtailments due to lack of system reserves are much larger than curtailments due to lack of grid capacity in the Mainland Spain power system.

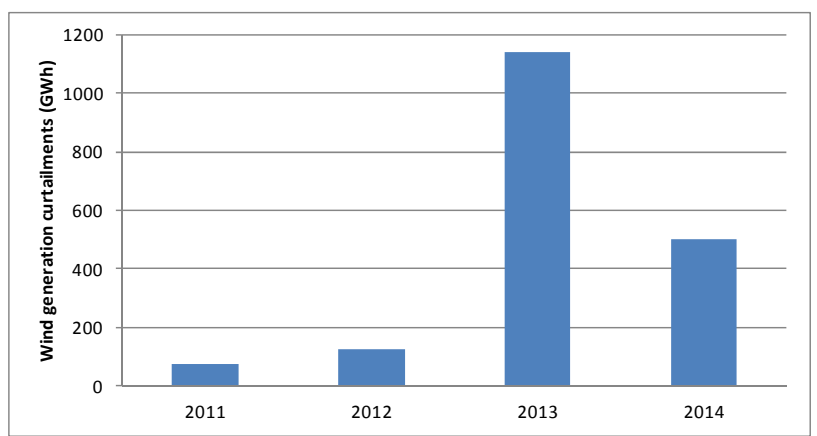

Figure 2: Wind generation curtailments due to constraint management in real time.

The number of hours with wind generation curtailments is worth to be investigated. Figure 3 displays the wind generation curtailments duration curves from 2011 through 2014. It indicates that the number of hour with wind generation curtailments was around 500 hours in 2013.

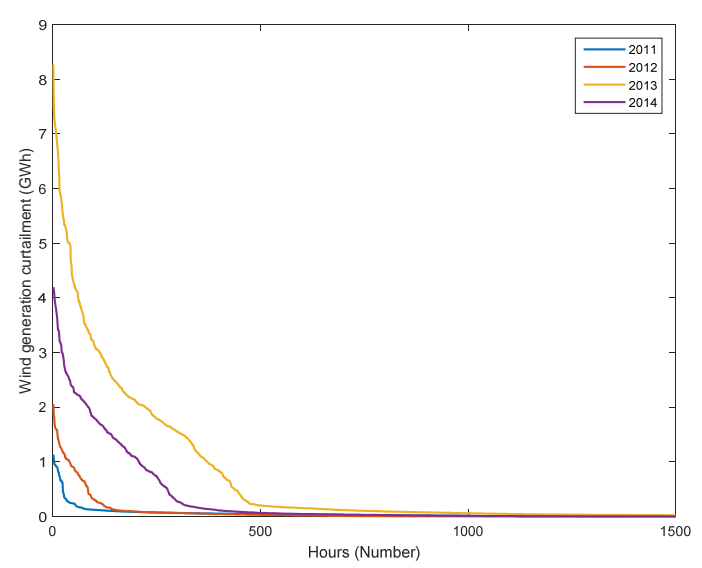

Figure 3: Past wind generation curtailments-duration curves.

The historical analysis of wind generation curtailments in the Mainland Spain power system has provided indications of upper bounds of the magnitude and duration of wind curtailments: $1000 \mathrm{GWh}$ and 500 hours.

\section{The ROM model}

Future wind generation curtailments are estimated using the ROM Model (Reliability and Operation Model for Renewable Energy Sources).

The model objective is to determine the technical and economic impact of intermittent generation (IG) and other types of emerging technologies (active demand response, electric vehicles, concentrated solar power, and solar photovoltaic) into the medium-term system operation including reliability assessment. Results consist of generation output including IG surplus, pumped storage hydro and storage hydro usage, and adequacy reliability measures. The benefits associated to improve IG predictions can also be determined by changing the forecast error distributions and re-running the model.

The main features of the model:

- A daily stochastic optimization model followed by a sequential hourly simulation. This system modeling in two phases reproduces the usual decision mechanism of the system operator. Detailed operation constraints such as minimum load, ramprate, minimum up-time and downtime of thermal units and power reserve provision are included into the daily stochastic unit commitment model. The hourly simulation is run for the same day to account for IG production errors, demand forecast errors and unit failure and therefore revising the previous schedule.

- A chronological approach to sequentially evaluate every day of a year. Decisions above this scope as the weekly scheduling of pumped storage hydro plants are done internally in the model by heuristic criteria. Yearly hydro scheduling of storage hydro plants is done by higher hierarchy models, as for example, a hydrothermal scheduling model.

Other features (although they will not be used in this study) of the ROM model are:

- The transmission network is represented by a DC load flow with ohmic losses approximated by a piecewise linear function.

- Monte Carlo simulation of many yearly scenarios that deal with IG or hydro inflows stochasticity

Figure 4 shows both the input and output data sets of the ROM model. 


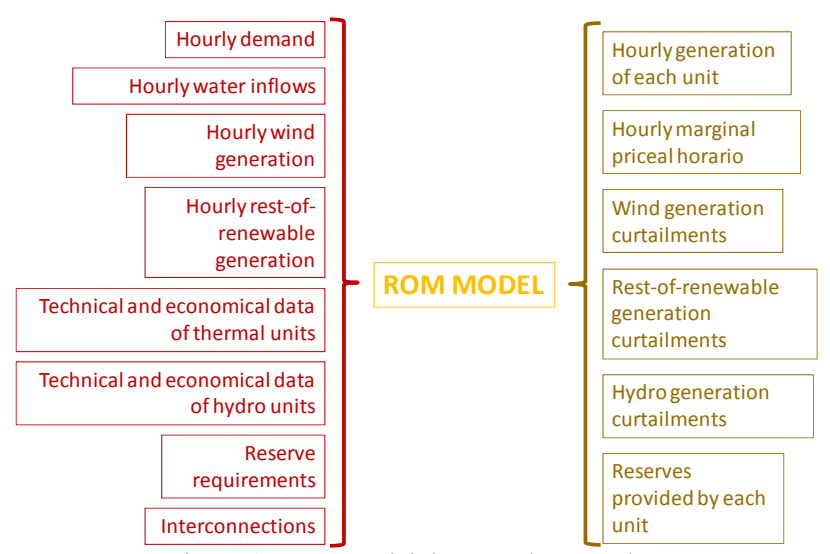

Figure 4: ROM model: input and output data

The accuracy of the ROM model is assessed simulating the 2014 scenario of the Mainland Spain power system [4]. Table I compares the actual and the simulated generation dispatch. Each technology share in the generation dispatch is highlighted. The maximum difference between actual and simulated technology share is $2 \%$. Table II compares the actual and simulated average marginal prices. The difference is less than $5 \%$. Table III compares the curtailments. The simulated wind generation curtailment is very close to the actual value. Hence, we can ensure the accuracy of the ROM model together with the considered input data set.

Table I: Comparison of actual and simulation results of 2014 scenario: generation.

\begin{tabular}{|c|c|c|}
\cline { 2 - 3 } \multicolumn{1}{c|}{} & \multicolumn{2}{c|}{ Generation (GWh) } \\
\cline { 2 - 3 } \multicolumn{1}{c|}{} & REE & ROM \\
\hline Hydro & 35503 & 35204 \\
\hline Nuclear & 54782 & 60219 \\
\hline Coal & 41058 & 33791 \\
\hline Combined cycle & 21120 & 25629 \\
\hline Wind & 51125 & 50621 \\
\hline Other RES & 50112 & 50112 \\
\hline
\end{tabular}

\begin{tabular}{|c|c|c|}
\cline { 2 - 3 } \multicolumn{1}{c|}{} & \multicolumn{2}{c|}{ Generation (\%) } \\
\cline { 2 - 3 } \multicolumn{1}{c|}{} & REE & ROM \\
\hline Hydro & 14 & 14 \\
\hline Nuclear & 22 & 24 \\
\hline Coal & 16 & 13 \\
\hline Combined cycle & 8 & 10 \\
\hline Wind & 20 & 20 \\
\hline Other RES & 20 & 20 \\
\hline
\end{tabular}

Table II: Comparison of actual and simulation results of 2014 scenario: marginal price.

\begin{tabular}{|c|c|c|}
\cline { 2 - 3 } \multicolumn{1}{c|}{} & \multicolumn{2}{c|}{ (€/MWh) } \\
\cline { 2 - 3 } \multicolumn{1}{c|}{} & REE & ROM \\
\hline Marginal price & 43.47 & 45.52 \\
\hline
\end{tabular}

Table III: Comparison of actual and simulation results of 2014 scenario: wind generation curtailments.

\begin{tabular}{|c|c|c|}
\cline { 2 - 3 } \multicolumn{1}{c|}{} & \multicolumn{2}{c|}{ Curtailments (GWh) } \\
\cline { 2 - 3 } \multicolumn{1}{c|}{} & REE 2014 & ROM 2014 \\
\hline Wind & 502.6 & 503.8 \\
\hline Other RES & 0 & 0 \\
\hline Hydro & 0 & 1 \\
\hline
\end{tabular}

\section{Estimation of future wind generation curtailments in the mainland Spain power system}

Future wind generation curtailments will be estimated in the short- and medium- term time horizons: 2020 and 2030 respectively.

\subsection{0 scenario}

In the short-term time horizon (2020), only demand variation and small variation of installed capacity will take place. Table IV details the assumed installed capacity in 2020 [5]. It is compared with the installed capacity in 2014. Several study cases have been considered in the 2020 time horizon depending on the demand growth, the hydro production and wind production profiles. Low, average and high demand growth assumes yearly demand growth of $1.7 \%, 1.9 \%$ and $2.3 \%$ respectively [5]. Up to nine study cases have been considered. Table $\mathrm{V}$ provides the attributes of those nine cases.

Table IV: Installed capacity at 2020.

\begin{tabular}{|c|c|c|c|c|}
\hline \multirow{2}{*}{ Technology } & \multicolumn{4}{|c|}{ Installed capacity } \\
\cline { 2 - 5 } & \multicolumn{2}{|c|}{$\mathbf{2 0 1 4}$} & \multicolumn{2}{|c|}{$\mathbf{2 0 2 0}$} \\
\hline Hydro & (MW) & (\%) & (MW) & (\%) \\
\hline Nuclear & 17786 & 17 & 19058 & 18 \\
\hline Coal & 7866 & 8 & 7866 & 8 \\
\hline Combined cycle & 10972 & 11 & 10270 & 10 \\
\hline Wind & 25353 & 25 & 19272 & 19 \\
\hline Biomass and cogeneration & 22845 & 22 & 27650 & 27 \\
\hline Small hydro & 8085 & 8 & 8644 & 8 \\
\hline Solar & 2105 & 2 & 2300 & 2 \\
\hline Total & 6728 & 7 & 8090 & 8 \\
\hline
\end{tabular}

Table V: Features of 2020 scenarios.

\begin{tabular}{|c|c|c|c|}
\hline \multicolumn{5}{|c|}{ Study cases } \\
\hline Name & $\begin{array}{c}\text { Yearly demand } \\
\text { growth }\end{array}$ & $\begin{array}{c}\text { Yearly hydro } \\
\text { generation } \\
\text { profile }\end{array}$ & $\begin{array}{c}\text { Yearly wind } \\
\text { generation } \\
\text { profile }\end{array}$ \\
\hline Case 1 & Low & Average & 2014 \\
\hline Case 2 & Medium & Average & 2014 \\
\hline Case 3 & High & Average & 2014 \\
\hline Case 4 & Average & Average & 2014 \\
\hline Case 5 & Average & High & 2014 \\
\hline Case 6 & Average & High & 2011 \\
\hline Case 7 & Average & High & 2012 \\
\hline Case 8 & Average & High & 2013 \\
\hline Case 9 & Average & High & 2014 \\
\hline
\end{tabular}

Table VI summarizes the ROM model wind generation curtailments (GWh and hours) for the nine cases proposed in Table V. Higher demand growth means lower wind generation curtailment. In contrast, higher hydro inflows results in higher wind generation curtailments. It has also found that the hourly wind generation affects significantly to the wind generation curtailments. Wind generation curtailments are between 440 and $3680 \mathrm{GWh}$ and use to take no longer than 900 hours per year. Figure 5 displays the wind generation curtailment duration curves that provide a first-a-glance understanding of the magnitude and duration of wind generation curtailment. 
Table VI: Summary of the simulation results of 2020 study cases.

\begin{tabular}{|c|c|c|c|c|c|}
\hline \multicolumn{7}{|c|}{ Study cases } \\
\hline Name & $\begin{array}{c}\text { Yearly demand } \\
\text { growth }\end{array}$ & $\begin{array}{c}\text { Yearly hydro } \\
\text { generation } \\
\text { profile }\end{array}$ & $\begin{array}{c}\text { Yearly wind } \\
\text { generation } \\
\text { profile }\end{array}$ & $\begin{array}{c}\text { Wind } \\
\text { curtailments } \\
\text { (GWh) }\end{array}$ & $\begin{array}{c}\text { Wind } \\
\text { curtailments } \\
\text { (hours) }\end{array}$ \\
\hline Case 1 & Low & Average & 2014 & 1,152 & 584 \\
\hline Case 2 & Medium & Average & 2014 & 882 & 507 \\
\hline Case 3 & High & Average & 2014 & 444 & 287 \\
\hline Case 4 & Average & Average & 2014 & 882 & 507 \\
\hline Case 5 & Average & High & 2014 & 992 & 577 \\
\hline Case 6 & Average & High & 2011 & 3,533 & 891 \\
\hline Case 7 & Average & High & 2012 & 3,679 & 896 \\
\hline Case 8 & Average & High & 2013 & 2,025 & 708 \\
\hline Case 9 & Average & High & 2014 & 992 & 577 \\
\hline \hline
\end{tabular}

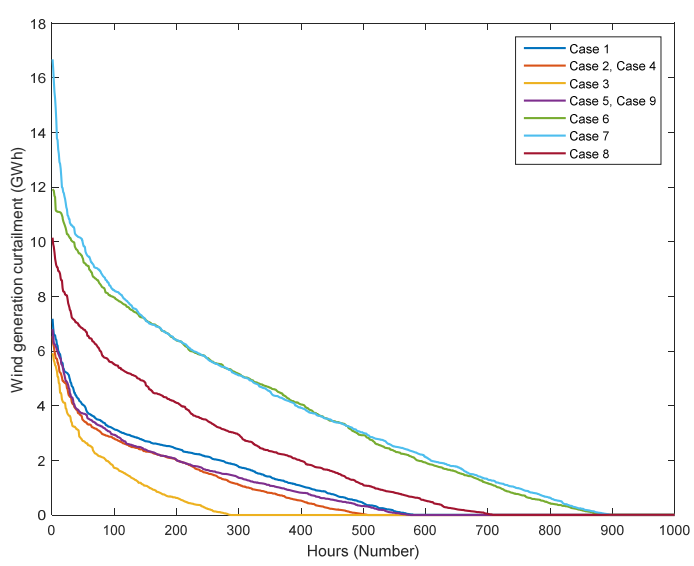

Figure 5: 2020 wind generation curtailments-duration curves.

\section{$4.2 \quad 2030$ scenarios}

In the medium-term time horizon (2030), significant variation of installed capacity will take place together with the demand growth. Two visions of the evolution of the installed capacity are considered [6]. Table VII details the assumed installed capacity in 2030. It is also compared with the installed capacity in 2014. Several cases will be considered in the 2030 time horizon depending on the demand growth, the hydro production and installed capacity evolution. Up to nine study cases will be considered. Table VIII provides the attributes of those nine cases. Table IX summarizes the ROM model wind generation curtailments (GWh and hours) for the nine cases proposed in Table VIII. Highly renewable vision 3 results in huge wind generation curtailment. Otherwise, wind generation curtailments are very low. Figure 6 confirm the clear distinction between visions 1 and 3 of the evolution of the installed capacity.

Table VII: Installed capacity at 2030.

\begin{tabular}{|c|c|c|c|c|c|c|}
\hline \multirow{2}{*}{ Technology } & \multicolumn{7}{|c|}{ Installed capacity } \\
\cline { 2 - 7 } & \multicolumn{2}{|c|}{$\mathbf{2 0 1 4}$} & \multicolumn{2}{c|}{$\mathbf{2 0 3 0}$ (Vision 1) } & \multicolumn{2}{|c|}{$\mathbf{2 0 3 0}$ (Vision 3) } \\
\cline { 2 - 7 } & (MW) & (\%) & (MW) & (\%) & (MW) & (\%) \\
\hline Hydro & 17786 & $17 \%$ & 23200 & $16 \%$ & 25100 & $14 \%$ \\
\hline Nuclear & 7866 & $8 \%$ & 7100 & $5 \%$ & 7100 & $4 \%$ \\
\hline Coal & 10972 & $11 \%$ & 4800 & $3 \%$ & 2600 & $1 \%$ \\
\hline Combined cycle & 25353 & $25 \%$ & 42900 & $31 \%$ & 52900 & $29 \%$ \\
\hline Winf & 22845 & $22 \%$ & 35200 & $25 \%$ & 48000 & $26 \%$ \\
\hline Biomass and cogeneration & 8085 & $8 \%$ & 8644 & $6 \%$ & 8644 & $5 \%$ \\
\hline Small hydro & 2105 & $2 \%$ & 2300 & $2 \%$ & 2300 & $1 \%$ \\
\hline Solar & 6728 & $7 \%$ & 16400 & $12 \%$ & 37000 & $20 \%$ \\
\hline \hline
\end{tabular}

Table VIII: Features of 2030 study cases

\begin{tabular}{|c|c|c|c|}
\hline \multicolumn{5}{|c|}{ Study cases } \\
\hline Name & $\begin{array}{c}\text { Yearly demand } \\
\text { growth }\end{array}$ & $\begin{array}{c}\text { Yearly hydro } \\
\text { generation } \\
\text { profile }\end{array}$ & $\begin{array}{c}\text { Renewable } \\
\text { generation } \\
\text { development }\end{array}$ \\
\hline Case 1 & Low & Average & Vision 1 \\
\hline Case 2 & Low & Average & Vision 3 \\
\hline Case 3 & Average & Average & Vision 1 \\
\hline Case 4 & Average & Average & Vision 3 \\
\hline Case 5 & High & Average & Vision 1 \\
\hline Case 6 & High & Average & Vision 3 \\
\hline Case 7 & Average & High & Vision 1 \\
\hline Case 8 & Average & High & Vision 3 \\
\hline
\end{tabular}

Table IX: Summary of the simulation results of the 2030 study cases.

\begin{tabular}{|c|c|c|c|c|c|}
\hline \multicolumn{7}{|c|}{ Study cases } \\
\hline Name & $\begin{array}{c}\text { Yearly demand } \\
\text { growth }\end{array}$ & $\begin{array}{c}\text { Yearly hydro } \\
\text { generation } \\
\text { profile }\end{array}$ & $\begin{array}{c}\text { Renewable } \\
\text { generation } \\
\text { development }\end{array}$ & $\begin{array}{c}\text { Wind } \\
\text { generation } \\
\text { curtailments } \\
\text { (GWh) }\end{array}$ & $\begin{array}{c}\text { Wind } \\
\text { generation } \\
\text { curtailments } \\
\text { (Hours) }\end{array}$ \\
\hline Case 1 & Low & Average & Vision 1 & 467 & 225 \\
\hline Case 2 & Low & Average & Vision 3 & 20,406 & 3,210 \\
\hline Case 3 & Average & Average & Vision 1 & 215 & 109 \\
\hline Case 4 & Average & Average & Vision 3 & 17,958 & 2,896 \\
\hline Case 5 & High & Average & Vision 1 & 63 & 38 \\
\hline Case 6 & High & Average & Vision 3 & 13,605 & 2,335 \\
\hline Case 7 & Average & High & Vision 1 & 305 & 155 \\
\hline Case 8 & Average & High & Vision 3 & 18,753 & 2,987 \\
\hline
\end{tabular}

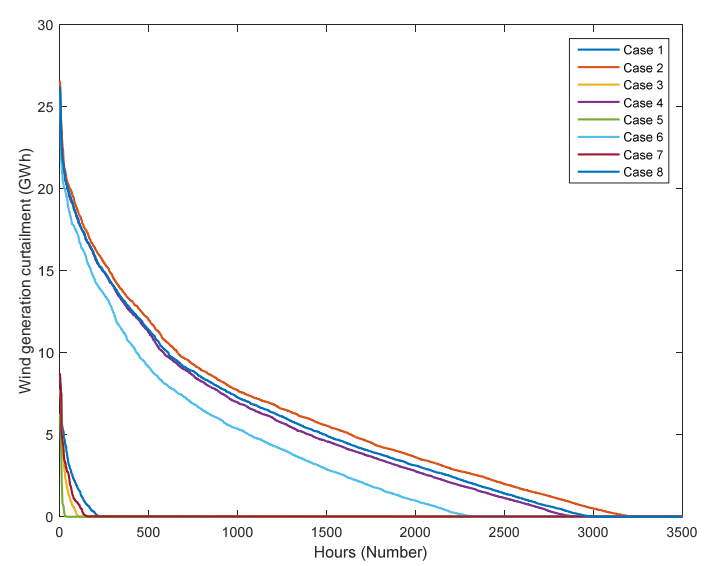

Figure 6: 2030 wind generation curtailments-duration curves.

\section{Economic analysis of P2G plants}

The economic feasibility of $\mathrm{P} 2 \mathrm{G}$ plant does not only depend on the number of hours that can operate. There are other factors that affect it. An interactive tool has been designed to assess the economic feasibility of a P2G plant and to conduct sensibility studies that provide a better understanding of the factors that determine it. The internal rate of return (IRR) of the investment is proposed to assess the economic feasibility of a $\mathrm{P} 2 \mathrm{G}$ plant [8].

The input data to the tool are:

- Operation mode:

- Operation when wind generation is curtailed

- Operation when the electricity price is below a threshold price

- Features of the P2G plant

- $\quad$ Rating (MW)

- Investment cost $(€ / \mathrm{kW})$

- $\quad$ Operation and maintenance costs $(€ /$ año) 
- Efficiency of the conversion of electrical energy into natural gasl $\eta \mathrm{P} 2 \mathrm{G}$ (MWhgas/ MWhelec)

- Minimum number of consecutive operating hours of electrolyzer

- Output of ROM model

- Minimum buying price of electricity (€/MWh) if operates when wind generation is curtailed

- Maximum buying prize of electricity $(€ / M W h)$ if operates when electricity is below a threshold price

- Selling price of natural gas (€/MWhgas)

- Maturity period of investment (number of years)

- Profibility threshold (\%)

- Range of operating hours

- Ranges of buying electricity price (€/MWh)

- Range of selling price of natural gas (€/MWhgas)

The tool will be illustrated assuming case 4 of 2030 scenario. The features of the $\mathrm{P} 2 \mathrm{G}$ are [9]:

- Rating = $2 \mathrm{MW}$

- Investment cost $=2500 € / \mathrm{kW}$

- Efficiency of the conversion of electrical energy into natural gas $\eta \mathrm{P} 2 \mathrm{G}=0.66 \mathrm{MWhgas} / \mathrm{MWhelec}$

- Selling price of natural gas $=20 € /$ MWhgas

- Buying price of electricity $=5 € /$ MWhelec

- Maturity period of investment $=20$ years

- Profibility threshold $=2 \%$

Figure 7 displays the IRR as a function of the seller price of natural gas. The profibility threshold of $2 \%$ is also represented. The plant IRR will be over the profibility threshold if the seller natural gas is over $80 € /$ Mwhgas.

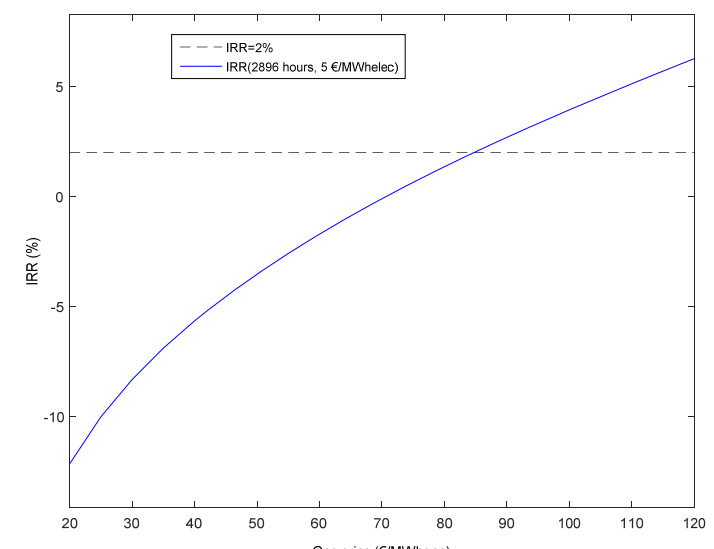

Figure 7: Internal rate of return as a function of natural gas prices.

The impact of the operating hours of the plant is investigated now. Figure 8 shows the IRR as a function of the seller price of natural gas for two scenarios of operating hours (3000 and 3400 hours). As the operating hours increase, the profibility threshold is achieved for lower selling price of natural gas.

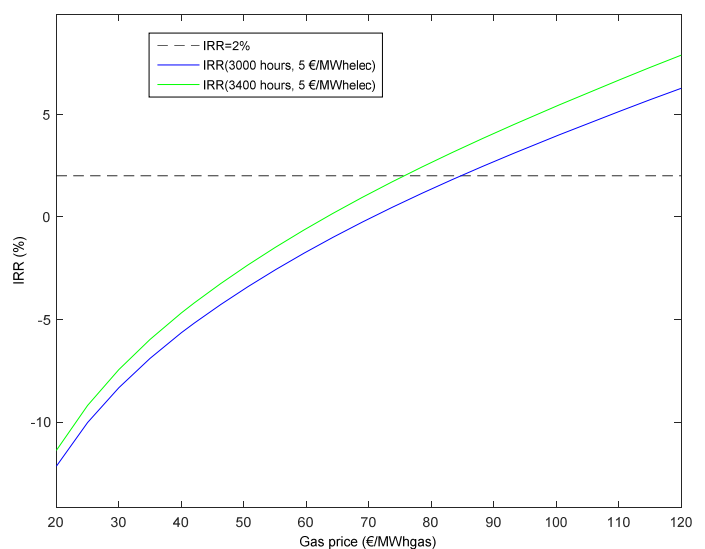

Figure 8: Internal rate of return as a function of natural gas prices and the hours of wind generation curtailment.

The impact of the buying electricity price is discussed now. Figure 9 shows the IRR as a function of the buying price of electricity (5 and $10 € /$ MWhelec). As the operating buying price of electricity increase, the profibility threshold is achieved for higher selling price of electricity.

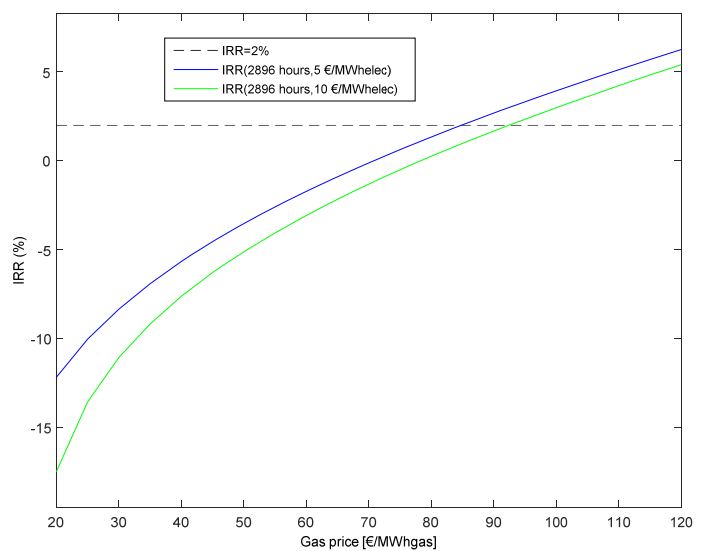

Figure 9: Internal rate of return as a function of natural gas prices and the buying electricity price.

\section{Conclusions}

This paper has presented the results of a study of the development perspectives of $\mathrm{P} 2 \mathrm{G}$ in Spain. The study has comprised: the estimation of wind generation curtailments in future scenarios of the Mainland Spain power system (2020 and 2030), the identification of the $\mathrm{CO} 2$ sources and the economic analysis of typical $\mathrm{P} 2 \mathrm{G}$ plants.

\section{References}

[1] A. Varone, M. Ferrari, "Power to liquid and power to gas: An option for the German Energiwende", Renewable and Sustainable Energy Reviews, Vol. 45, pp. 207-218, 2015.

[2] A. Ramos,'ROM: Reliability and Operation Model for Renewable Energy Sources", http://www.iit.comillas.edu/aramos/ROM.htm.

[3] Red Eléctrica de España, "Sistema de Información del Operador del Sistema (e-sios)", Ficheros mensuales "grpbfmed" para todos los meses del 2011 al 2014. Disponibles en: http://www.esios.ree.es/web-publica/ en la pestaña "Publicaciones", "Liquidaciones", "Liquidaciones mensuales del OS". 
[4] Red Eléctrica de España, "Avance del informe del sistema eléctrico español 2014”, 23 de diciembre del 2014. 2014

[5] Ministerio de Industria, Turismo y Comercio, "Planificación energética - Plan de desarrollo de la red de transporte de energía eléctrica 2015-2020. Versión preliminar", disponible en: http://www.minetur.gob.es/energia/planificacion/Planificacionelec tricidadygas/desarrollo2015-2020/Paginas/desarrollo.aspx.

[6] ENTSO-E, "SCENARIO OUTLOOK AND ADEQUACY FORECAST 2014-2030", disponible en:https:/www.entsoe.eu/fileadmin/user_upload/_library/SDC/SO AF/140602 SOAF\%202014-2030.pdf.

[7] I. Egido, F. Fernández-Bernal, P. Centeno, L. Rouco, "Maximum Frequency Deviation Calculation in Small Isolated Power Systems", IEEE Transactions on Power Systems, Vol. 24, No. 4, pp. 1731-1738.

[8] D. Luenberger, "Investment Science", Prentice Hall.

[9] C. Folke, "Experience on Power to gas in Germany and the future steps", Disponible en: http://backend.storeproject.eu/uploads/docs/eusew-2013-presentations/folkepresentation-eusew-2013.pdf.

\section{Acknowledgements}

The work reported in this paper was developed within the framework of RENOVAGAS research funded by the Spanish Ministry of Economy, Industry and Competitiveness under the "Retos-Colaboración 2014" program. This support is gratefully acknowledged. Prof. A. Ramos made available to the authors of this paper the ROM model. Without the ROM model the comprehensive set of simulations reported in the paper would not have been possible. 